\title{
Study of the natural and cultural space of the Sakha ethnos
}

\author{
Sardana Fedorova $^{1 *}$, Nina Konopleva ${ }^{2}$ \\ ${ }^{1}$ M.K. Ammosov North-Eastern Federal University, 58 Belinsky str. Yakutsk, 677000, Russia. \\ ${ }^{2}$ Vladivostok State University of Economy and Service, 41 Gogolya str. Vladivostok, 690014, Russia.
}

\begin{abstract}
The article is devoted to the problem of preserving interethnic tolerance and cultural heritage of the Republic of Sakha (Yakutia), which is relevant for modern theory and history of culture. The authors analyze theoretical and methodological approaches to the essence of the concepts: ethnos, ethnicity, cultural space, natural and cultural heritage. They demonstrate the peculiarities of the linguistic and cultural heritage of Yakutia, its possibilities in positioning the region and promoting the culture of Yakut people.
\end{abstract}

\section{Introduction}

Transition periods in culture and history are stages of the evolutionary development of society, its ascension to a higher stage of development, but they are characterized by a contradictory interaction between the previous and new stages of evolution, between traditional and newly formed cultural values.

The XX-XXI centuries are characterized by the intensive development of globalization processes and the erosion of cultural boundaries. This period actualizes the need to consider the culture of ethnic groups that consistently and purposefully preserve their cultural heritage and tolerant principles of intercultural interaction.

In modern scientific works, there are many studies of ethnicity analysis. We believe that an interdisciplinary cultural and anthropological approach is the most promising way to study multinational regions that maintain the territorial identity of cultures of all those living folks in the region. It even combines externally antagonistic concepts and factors to study the regional culture.

\section{Materials and methods}

To study the natural and cultural space of the Sakha ethnos, we will initially consider the term of ethnos. This term originated from the ancient Greek words: a people, a group of people, a tribe, etc. In the VI-V centuries BC, ethnic groups were considered peoples of non-Greek origin. Since the 19th century, this term has been used in scientific literature in terms of "people". In the twentieth century, S.M. Shirokogorov gave the following definition of "ethnos". This is a form of human development and existence, manifested in the unification of people into a group, characterized by the recognition of the unity of their origin, the presence of traditions preserved by traditions different from other groups of customs and their way of life, as well as speaking the same language [1].

There are a number of theories of ethnos, for example, the passionary theory of L.N. Gumilyov. According to L.N. Gumilyov, an ethnos is a biophysical entity with social characteristics, a closed but discrete system, which received an energy charge once and wasted it, acquiring equilibrium with the environment or decaying [2].

\section{Results and Discussion}

According to the dualistic concept of Yu.V. Bromley, an ethnos is manifested by combined characteristics that unite language, culture, self-awareness, as well as conditions for the emergence and existence, including naturalgeographic-territorial, economic-social, state-legal aspects, etc. [3, p. 11]. The term ethnikos, in the viewpoint of $\mathrm{Yu} . \mathrm{V}$. Bromley, is characterized by historical stability, the stability of linguistic, cultural and mental characteristics, the presence of self-awareness among the representatives of the ethnos, manifested, in particular, in the awareness of their unity and difference from other groups and recorded in the self-name (ethnonym) [3, P.14].

From the point of view of S.A. Arutyunova an ethnos is the ability of peoples to adapt to a specific habitat and not only to adapt to natural factors (landscape), but also to economic, political, socio-cultural characteristics. Together with N.N. Cheboksarov, they believe that ethnos plays the role of an information filter, forming value ideas about the world, norms of behavior, values that protect a person in complex information situations, i.e. ethnos is a stabilizer of socio-normative information, serves to protect representatives of an ethnos from life 
problems, socio-cultural, economic, political instability and uncertainty [4, pp. 7-10].

If we rely on this theory, as well as on globalization cultural processes, the actualized interest of Russian scientists in recent years in the concepts of "ethnos" and "ethnicity" is quite explainable. This happens due to the fact that in the transitional historical periods, when the old system of values is crumbling, and the new one has not yet taken shape, various kinds of protection are very important for a person and society. The actualization of the principles of ethnic culture, traditional cultural values and behavioral norms can be the source of such protection.

In addition to the concept of "ethnos" in science, the term "ethnicity" is used.

According to S.E. Rybakov, ethnicity is not just the recognition of a certain ethnos, but it is a personal striving for this identification and its influence on the corresponding social activity [5, p. 11]. In modern science, the problem of ethnicity (ethnic identity) is considered in the context of a number of approaches: functional combining constructivist and pragmatist-instrumentalist theories; ontological (primordial) (sociobiological and evolutionary-historical directions); anthropological; instrumentalist (constructivist); sociological; cultural.

The primordialist paradigm appeared in the 19th century in Germany, and the term was introduced into science by American sociologist E. Shils, who used it to characterize family relations. Most often, this paradigm in the analysis of ethnicity is used in the formulation of the founder of interpretive anthropology K. Geertz: "In every society at all times, some attachments stem more from a feeling of natural, some would say - spiritual closeness than from social interaction" [cit. according to 6 , p. 5]. This quote clearly demonstrates to us the primordiality of ethnic ties, correlated by the supporters of this paradigm with the fact that ethnicity is determined by the genetic code, the result of evolution, the need for the survival of members of a related group [1, p.92]. Moreover, primordialist theories are divided into evolutionary-historical and natural (sociobiological) directions. Adherents of the sociobiological direction believe that ethnicity is a primordial (primordial, that is, primordial) objective given due to geographical and genetic aspects that contribute to kin selection ("nepotism") and the expansion of family ties (Pierre van den Berge). "With the progressive growth of the size of the human community, the boundaries of the ethnos became wider, the ties of kinship were accordingly blurred ... However, the need for collectivity, wider than the immediate circle of relatives based on biological origin, continues to be present even in modern mass industrial societies" [7, p. 35.]. According to sociobiologists - supporters of this trend, nepotism is genetically encoded due to the altruism of a representative of an ethnic group, which contributes to sacrificing oneself for the sake of saving the group. At the same time, this representative loses the ability to transfer its genes to the next generations, but increases this ability in blood relatives, saving the family in difficult life situations. According to van den Berg, it is precisely kinship selection and deep affective attach- ment of people that are decisive in the formation of ethnicity. In Russian ethnology, the concept of L.N. Gumilyov, who, on the one hand, regarded the ethnos as a biological phenomenon, but on the other hand, considered the culture created by the ethnos as a social phenomenon.

Supporters of the evolutionary-historical direction of primordialism correlate ethnicity with Herder's (IG Herder) interpretation of the people, understood as a social community that arises as a result of the unity of "blood and soil." This direction of primordialism includes the views of Russian scientists S.M. Shirokogorov and Yu.V. Bromley (the definition of the ethnic group was given above). According to the views of representatives of the evolutionary-historical direction, the most significant factors of ethnicity are the common language and territory.

At the same time, for our research it is very important to understand the natural and social conditions of the common territory, expressed in the peculiarities of culture, world outlook, value attitudes, everyday life, economic activity, ethical normative principles of behavior. Thus, the ontological approach is based on the cultural unity of ethnic groups, and hence their ontological reality, consideration of the reasons for the constancy and rootedness of the ethnos.

In the anthropological approach of S.E. Rybakov notes that "... the individual ethnic is immanent to a person as such, as an indispensable and inalienable structure of personality in general, but it is at the same time an acquired property when it comes to a single individual" [5, p. 12]. In this regard, he substantiates the need to provide connections, channels of information transmission (diachronic and synchronous) between carriers of ethnicity, since ethnicity, in his opinion, is not inherited, but "is reborn in the process of socialization of each individual person".

According to representatives of instrumentalism, the basis for the formation of the ethnic identity is the differences between groups of people, which affect intergroup relations and intensify the political activity of ethnic groups. This theory can be attributed to the sociological theories of ethnicity. Adherents of instrumentalism believe that ethnicity is a product of ethnic myths created by the elite to gain power, while the elite relies on the cultural values of the ethnos, but uses them in their own aspirations. Moreover, these concepts are based on a number of psychological theories, considering ethnicity as a method of therapy with the aim of restoring political and cultural equality in society. This approach in instrumentalist concepts is based on the theory of rational choice, which, when correlated with the analysis of ethnic problems, is supported by David Layton. He substantiates that a number of identities conditioned by gender, religious, class, family, ethnic factors are simultaneously connected in each individual. Depending on the situation, a person makes a reasonable choice based on the corresponding identity. Layton believes that there is no stable basis in identities, including ethnic ones, each person acts in accordance with his own needs and goals, and it is they who dictate his 
method of action. Instrumentalism undoubtedly belongs to the sociological theories of ethnicity, which, according to N.G. Skvortsov, in contrast to anthropological studies, is used in research "... a wider arsenal of research tools" [8, p. 23]. In particular, the explanation of social life is based on the study of an objective reality independent of the subject (objectivist scheme), the priority of social structures and institutions, or a subjectivist concept based in research on the principles of individualism and substantiating the subject as a basic basis in social cognition (Ibid.).

Since an ethnos is a socio-cultural community, then, undoubtedly, in their research ethnologists also use culturological concepts that address the problems of the structure and existence of folk culture. Ethnologists accept the thesis of the flexibility and variability of cultural traditions. As a result, researchers should be faced with the question of what processes occur in an ethnos during the period of cultural transformations. In these studies, the axiological approach is extremely important, which allows ethnology to address the problem of values in the formation of the ethnic picture of the world and its transformations.

The most significant fact in the analysis of ethnoses and ethnicity is an interdisciplinary approach that combines externally even antagonistic concepts and factors: natural; biological; social. At the same time, we rely on an integrative cultural-anthropological approach, but put ethnicity in the first place, as we noted above: "It is not an ethnos that forms the ethnicity of individuals; on the contrary, the ethnos itself is born from ethnicity as an anthropological quality" [5, p. 12].

Ethnicity is a characteristic that reflects the qualitative and quantitative processes of identifying an individual with a specific ethnic group and includes:

a) grounds for attributing an individual to a particular ethnic group. This basis is, first of all, language and ethnic culture;

b) the result of this assignment. This result is an ethnic identity that has certain characteristics - value orientations and attitudes, behavioral norms, ethnic mentality;

c) the strength of the impact of ethnic selfidentification on the personality structures and behavior of the individual.

In our study, of course, we do not set ourselves the goal of exploring all these aspects of the Yakut ethnos. We are primarily interested in natural and cultural factors, on the one hand, that contributed to the formation of this multiethnic nation. And on the other hand, the characteristics of its ethnicity is traditional, preserved to this day, as well as transformed in modern culture, as well as heritage factors that can be used to improve the regional image, advance the territory, using modern tourism technologies.

The problem of cultural heritage is considered in many UNESCO documents, and initially they only dealt with objects of material heritage, and the problem of the spiritual heritage of humanity as a whole and individual ethnic group was not considered at all. Moreover, for the first time in 1954, the Hague Convention was adopted, which substantiated the issues of protecting cultural property in the event of armed conflicts. Later, in 1962, the attention of the world community was directed to the elements of natural heritage, the principles of preserving beauty and natural landscapes were recommended. In 1972, the UNESCO Convention on the Combined Conservation of both Cultural and Natural Heritage was adopted.

It should be noted that initially, all documents lacked a definition of cultural heritage. In particular, the 1972 UNESCO Convention provided a detailed description of only types of cultural heritage:

- monuments: works of architecture, monumental sculptures and paintings, elements or structures of an archaeological nature, inscriptions, cave dwellings and groups of elements of outstanding universal value in terms of history, art or science;

- ensembles: groups of isolated or combined structures, architecture, the unity or connection of which with the landscape is of outstanding universal value from the point of view of history, art or science;

- places of interest: works of man or the joint creations of man and nature, as well as areas, including archaeological sites, of outstanding universal value from the point of view of history, art or science.

We define ethnicity as the result of qualitative and quantitative manifestations of identification processes that contribute to the acquisition by the nation of a regional identity characterized by certain values, behavioral norms, language, formed mentality, preserved customs, traditions, expressed their impact on the behavior and personal structures of the respective territory inhabitants.

The example of a region that retains its interethnic identity and tolerant relations of all ethnic groups living on the territory is the Republic of Sakha (Yakutia), where live Russians, Yakuts, Ukrainians, Tatars, small nationalities as Chukchas, Evens, Evenks, Yukagirs, etc.

Before studying the natural and cultural heritage of any region, it should be taken into account that initially this issue was dealt with by geographers who studied issues of the cultural landscape. So, in 1913, L.S. Berg during a report on Russian geographical society noted that one of the goals of geographical research is the study of natural and cultural landscapes, and he referred to cultural ones in which the person himself and his cultural works have an important role [7, p. 463-475]. He defined the landscape as an area in which the nature of the terrain, climate, vegetation and soil cover merge into a single harmonious whole, typically repeated throughout the known zone of the Earth [7, p. 471].

V.P. Semenov-Tien-Shan divided all landscapes into primitive, semi-wild, cultural, wild, and feral. $\mathrm{He}$ referred to the cultural landscapes that he called landscapes as those that were used by man and in which he voluntarily moved mineral, plant and animal elements, destroying some of them and replacing them in the corresponding territory with perfect works of his labor [9]. D.V. Bogdanov designated three groups of landscapes: primitive, slightly modified and cultural [10, pp. 300-321]. V.L. Kotelnikov etymologized landscapes into two groups: "changed", undergoing spontaneous transformations and "transformed", subjected to human- 
planned changes [11, pp. 144-157]. V.V. Dokuchaev, who for the first time carried out complex field studies of specific territories with the study of natural processes in their dynamics (1882-1898), developed the doctrine of natural-historical zones, which is based on the idea of natural zones (or landscapes). L.G. Ramensky identified a typological and regional (individual) interpretation of the landscape, according to which the landscape is a complex territorial system consisting of heterogeneous, but connected in space and developing as whole elementary natural complexes - epiphanies [12, p. 163]. In the future, two directions in understanding the natural and cultural heritage were divided and expressed the opinion that landscape scientists should direct their efforts to the study of small natural territorial complexes, that is, landscapes themselves, and specialists dealing with zoning issues should study territories, countries, specific regional zones. But in the future, under the influence of the works of A.G. Isachenko on the landscape as a "nodal unit" these two directions in the theoretical understanding of territories were combined, which allowed scientists to consider landscapes as territorial groups of the highest order and study them in the context of historical and spatial relationships [13, pp. 234-235].

Thus, scientific approaches and principles of landscape studies have great importance in the study of the natural heritage of territories.

As for cultural heritage, the analysis of the term demonstrates the absence of a single concept, its consideration in scientific articles and monographs in various contexts. In particular, E.N. Selezneva believes that the development of cultural heritage serves to actualize adaptive factors in the situation of transitional culture. E.A. Shumkova agrees with this. Cultural heritage includes material objects - structures, complexes, various man-made objects that are a source of value meanings of past generations: from anthropological, archaeological, aesthetic, ethnographic, historical scientific and artistic points of view. It can also be historical sites that are in the list of places containing artifacts: rock carvings, religious buildings, ancient settlements, necropolises, buildings and structures, works of monumental art, objects of landscape and architectural art. They are a source of information about the culture and life of peoples, that is, serving as a source of knowledge of future generations about ethnic culture.

Today there is a growing interest in the cultural heritage of the Russian Federation people. The Republic of Sakha (Yakutia) is a multinational republic. According to the results of 2021 of the Territorial Body of the Federal State Statistics Service of the Republic of Sakha (Yakutia), 981971 people live in the republic, and among them different native nationalities: Sakha - 352664, Dolgans - 1281, Evenks - 14938, Evens - 10850, Yukaghirs - 870, Chukchas - 477 [14].

The indigenous people of Yakutia mainly try to preserve their native language and unique cultural heritage. The ethno-cultural heritage is closely connected with native speakers. Also an integrated approach plays an important role: the preservation of the way of life of an ethnic group, identity, culture, customs, rituals, folklore and traditions.

All these elements of cultural heritage represent the material and spiritual culture that each ethnic group has, which have been passed down from generation to generation and have stood the test of time.

There is a notion that there is no folk without a language. The Government of the Republic carries out the great work on the preservation and development of languages and culture. In 1992, the law "On Languages" was adopted [15], in 1996 they established the Day of the Native Language and Writing (February 13). And in 2019 they approved the state program for the preservation and development of state and official languages in the republic until 2024 [16]. It is also important that the Evens, Evenk, Dolgan, Yukaghir and Chukchas languages were recognized as official in the places of traditional residence of the indigenous peoples of the North.

For the self-identification of any people, the key components are language and culture. And language is shown as meaning of communication of self-expression, creative ideas, forms a person to become original.

Since 2000, every year on February 21, we celebrate the International Mother Tongue Day. The main purpose of this event is to promote linguistic and cultural diversity and multilingualism.

If you look at the history, in 1822 they issued the Charter on the management of foreigners, where it was recorded that "all the foreign tribes living in Siberia, still called «yasachny», according to their varying degrees of civil education and their real way of life" were divided into three main categories. They are sedentary, nomadic and vagrant, with the endowment of each category with special rights and duties [17]. In this charter, it is noted that Yakuts - "nomadic foreigners", Yukaghirs, Evens, Evenks and other "grassroots foreigners" were classified as "vagrants" [18, p. 26.].

In the present time, many Evenks, Evens, Dolgans and Yukaghirs switch to the Yakut language, but nevertheless do not lose their northern identity. It most likely depends on the fact that they live separately and are engaged in their traditional farming: reindeer herding, fishing, hunting.

In the Republic of Sakha (Yakutia) in 2018, the law "On the Strategy of socio-economic development until 2032 with a target vision until 2050" was adopted [19]. Within the framework of this law, new approaches to the study of the natural and cultural space of the Yakut ethnic group are being considered. Preservation of the cultural heritage and unity of the multinational people of the Republic of Sakha (Yakutia), linguistic diversity, folk art, historical, cultural and literary heritage contribute to strengthening the civic identity and unity of the Yakut people. It creates conditions for the formation of a harmoniously developed personality that continues the traditions and customs of previous generations.

Thus, it is necessary to ensure the introduction of the cultural heritage of the republic, its traditions, including the national holiday Ysyakh, the masterpiece of the intangible heritage of UNESCO Olonkho, the unique 
inventions of the Yakut people Khomus and Choron, into the world cultural space.

The Government of the Republic is carrying out large-scale work to promote the advantages of the territory, the development of ethnic cultural traditions, the cultural heritage of the indigenous people of the Republic including the introduction of electronic training programs on the languages of the indigenous peoples of the North, digitalization of the linguistic and cultural heritage.

Effective use of recreational resources, as well as unique cultural monuments, respect for the traditions, customs, language and culture of their own and other people living in the Republic of Sakha (Yakutia) are the condition for the formation of a positive image in the representations of target audiences and the success of branding the territory. The creation of a territory brand, among other circumstances, has a pronounced social and economic character.

For tourists, the republic may be interesting, firstly, as the ethnicities preserved by the local people, the veneration of history and the memory of ancestors, traditions and customs, and only then natural attractions. The Sakha Republic acts as an independent brand in global symbolic exchanges.

The main direction of branding of the republic is the development of tourist infrastructure. In the capital of the republic, there are objects that form the basis of the regional brand. These are the Museum of the Institute of Permafrost Studies SB RAS; Yakut State United Museum of the History and Culture of the Peoples of the North named after Em. Yaroslavsky. There is also the National Art Museum of the Republic of Sakha (Yakutia); International Center of Khomus (harp) Music; Mammoth Museum; Museum of Music and Folklore of the Peoples of the Republic of Sakha (Yakutia). These also include the unique underground laboratory of the Institute of Permafrost, the Kingdom of Permafrost, etc. The central place of attraction, of course, is the Old Town, being a historical and architectural complex with many merchant houses and other buildings of the 19th century.

\section{Conclusion}

Undoubtedly, the work on identifying and branding historical and cultural heritage contributes to increasing the investment attractiveness of the region, contributes to solving the problem of employment, as well as the development of recreational and tourist attractiveness of the territory. At the same time, the system of creating ethno-cultural complexes can be considered both as an infrastructure of cultural and educational tourism, and as a resource for preserving and popularizing objects of natural and cultural heritage, contributing to the formation of positive foundations of interethnic relations.

\section{References}

1. S.M. Shirokogorov. Ethnos. Research on basic principles of change of ethnic and ethnographic phenomena (Vladivostok, 2001)

2. L.N. Gumilev. Ethnosphere: history of the people and the history of nature (Saint Petersburg, 2002)

3. Yu.V. Bromley. Ethnosocial processes: theory, history, modernity (Moscow, 1987)

4. S.A. Arutyunov. Peoples and cultures. Development and interaction. 243 (Moscow, 1989)

5. S.E. Rybakov. On the methodology of the study of ethnic phenomena.Ethnic Review, 5, (2000)

6. B.E. Wiener. Ethnicity: In search of a paradigm of research Ethnic Review, 4(5), (1998)

7. L.S. Berg. The subject and objectives of geography. Izvestiya RGO, 9, 463-475 (1915)

8. N.G. Skvortsov. Ethnicity: a sociological perspective, Sotsiologicheskie Issledovaniya, 1(23), (1999).

9. V.P. Semenov-Tien-Shansky. Region and country. 312 (Moskow-Leningrad.: GIZ, 1928)

10. D.V. Bogdanov. Cultural landscapes of the valleys of-the North-Western Pamirs and the possibilities of the transformation. Questions de geography, 24, 300-321 (1951)

11. V.L. Kotelnikov. The tasks of Soviet landscape studies in connection with the participation of geographers in the implementation of the Stalinist plan for the transformation de nature. Questions de geography, 23, 144 - 157 (1950)

12. L.G. Ramenskiy. Introduction to integrated Soil and geobotanical land study. (Moscow, 1938)

13. A.G. Isachenko. Basic questions de physical geography. (Leningrad, 1953)

14. Territorial body of the Federal State Statistics Service for the Republic of Sakha (Yakutia). Demography, retrieved from: https://sakha.gks.ru/folder/32348

15. Law of the Republic of Sakha (Yakutia) de October 16, 1992 No. 1170-XII "In languages in Republic of Sakha (Yakutia). retrieved from: https://docs.cntd.ru/document/804911252

16. Decree No. 901 of December 16, 2019 "On the state program of the Republic of Sakha (Yakutia). "Preservation and development of state and official languages in the Republic of Sakha (Yakutia) for 2020 - 2024"" retrieved from: https://docs.cntd.ru/document/561673207

17. The Charter on the management of foreigners (June 22, 1822) // The complete collection of laws of the Russian Empire. (Saint Petersburg, 1830)

18. S.I. Boyakova. The development of the Arctic and the peoples of Northeast Asia (XIX century 1917). (Novosibirsk, 2001)

19. The Law of the Republic of Sakha (Yakutia) of December 19, 2018 2077-Z N 45-VI "On the Strategy of socio-economic development of the Republic of Sakha (Yakutia) until 2032 with a target vision until 2050". retrieved from: https://docs.cntd.ru/document/550299670 